\title{
Anisotropic ionic conduction in composite polymer electrolytes filled with clays oriented by a strong magnetic field
}

\begin{abstract}
Shunsuke Kitajima ${ }^{1}$, Masahiro Matsuda ${ }^{1}$, Masafumi Yamato ${ }^{2}$ and Yoichi Tominaga ${ }^{1}$
To utilize the fascinating properties of clays, including their large surface areas, many dissociable cations in the interlayers and low-dimensional structure, we focused on controlling the orientation of clay layers in ion-conductive polymer electrolytes. The application of a strong magnetic field is one of the effective methods used to control the orientation of clay layers and to improve the ionic conductivity of the clay composites. In this study, two different composite films were obtained using different orientations of the magnetic field: perpendicular $\left(M_{\perp}\right)$ and parallel $\left(M_{/ l}\right)$ to the film surface. From two-dimensional wide-angle $\mathrm{X}$-ray diffraction measurements, the montmorillonite (MMT) layers preferentially oriented along the direction of the magnetic fields in the composites. There were substantial correlations between the conductivity and the ratio of MMT layers oriented along the direction of the conductivity measurement. The lowest conductivity was observed in the $\mathrm{M}_{/ /}$composite, whereas the $\mathrm{M}_{\perp}$ composite showed very good conductivity. The value was higher than that of the original electrolytes $\left(\mathrm{PMEO}_{10} \mathrm{LiClO} \mathrm{O}_{4}\right)$ at $30{ }^{\circ} \mathrm{C}$. These results clearly suggest that the orientation direction of the MMT layers toward the direction parallel to the conductivity measurement causes an improvement in the conductivity of the composites. In particular, the conductivity value of the $\mathrm{M}_{\perp}$ composite with 5 wt\% Li-MMT was $1.2 \times 10^{-5} \mathrm{~S} \mathrm{~cm}^{-1}$ at $30^{\circ} \mathrm{C}$, which was more than six times higher than the original electrolyte.
\end{abstract}

Polymer Journal (2013) 45, 738-743; doi:10.1038/pj.2012.207; published online 21 November 2012

Keywords: clay; magnetic field; orientation; polymer composite; solid polymer electrolyte

\section{INTRODUCTION}

Solid polymer electrolytes (SPEs) have attracted much attention as ion-conductive soft materials because of their safety (nonflammable and no leakage), flexibility and light weight. ${ }^{1,2}$ SPEs are therefore useful in novel lithium-ion secondary batteries. In the last three decades, there have been many studies of poly(ethylene oxide) (PEO)based SPEs with enhanced conductivity. ${ }^{3,4}$ Unfortunately, these SPEs have relatively low conductivity at room temperature and also low cation transference numbers. To overcome these problems, it is known that the addition of various nanosized ceramic fillers to the SPE is an effective method. ${ }^{5-8}$ In all ceramic fillers for SPEs, aluminum silicate clays of the smectite group, such as montmorillonite (MMT), are known to have useful properties and may be practical because the clay has a large surface area and a fine layer structure and has many dissociable cations in the interlayers. ${ }^{9-12}$ Many studies have been reported on $\mathrm{PEO} /$ clay composites in which the PEO chains reside between the nanolayers. For example, the ionic conductivity of $\mathrm{PEO} / \mathrm{Li}-\mathrm{MMT}$ at room temperature increased compared with the conventional $\mathrm{PEO} / \mathrm{LiBF}_{4}$ systems. ${ }^{11}$ This can be explained by fast segmental motion of the PEO chains in Li-MMT composites with weak temperature dependence. ${ }^{13-15}$ In our previous studies, supercritical $\mathrm{CO}_{2}$ and freeze-dried treatments are effective methods for further enhancement of the conductivity of the polyether/clay composites. ${ }^{16,17}$ The enhancement in the conductivity contributes to the improvement in the dispersion state of clay, which increases the number of mobile cations that are restricted by the negatively charged layers.

In contrast, some researchers have reported that the ionic conduction in clay composites shows high anisotropy and is different for the perpendicular and parallel directions with respect to the sample film surface. The conductivity of the parallel-oriented clay composites is significantly higher than that of the perpendicular-oriented ones. ${ }^{9,18}$ The anisotropic conduction is preferentially caused by the orientation of clay layers, which is due to the intrinsic low-dimensional structure. To utilize the low-dimensional function of clay in the SPE, control of the orientation state is required.

Here, we report the utilization of strong magnetic fields to control the orientation of dispersed clay layers in ion-conductive polymers

${ }^{1}$ Department of Organic and Polymer Materials Chemistry, Tokyo University of Agriculture and Technology, Tokyo, Japan and ${ }^{2}$ Department of Applied Chemistry, Tokyo Metropolitan University, Minami-Ohsawa, Tokyo, Japan

Correspondence: Dr Y Tominaga, Department of Organic and Polymer Materials Chemistry, Tokyo University of Agriculture and Technology, 2-24-16, Naka-cho, Koganei, Tokyo 184-8588, Japan.

E-mail: ytominag@cc.tuat.ac.jp

Received 27 July 2012; revised 19 September 2012; accepted 1 October 2012; published online 21 November 2012 
and determine the effect of the orientation on the conductivity. The application of magnetic fields is known to be particularly attractive for orienting high-aspect-ratio materials, such as clays, fibers and polymers, and is practical because of its nondestructive nature compared with typical methods such as mechanical shearing ${ }^{19}$ and the application of electric fields. ${ }^{20,21}$ The magnetic field orientation of clays and other inorganic materials have been extensively reported by Uyeda et al. ${ }^{22-24}$ Kimura et al. ${ }^{25}$ have also shown the potential of magnetic fields in the photochemistry of Rhodamine B intercalated in various types of clays. However, there are no reports on the orientation of clays in polymer composites and in ion-conductive materials using magnetic fields. In this study, we prepared amorphous polyether composite electrolytes filled with lithium MMT and evaluated the relationship between the conductivity and the direction of oriented MMT layers.

\section{EXPERIMENTAL PROCEDURE}

\section{Materials}

We used poly(ethylene glycol) monomethacrylate (Blemmer PE-350, $M_{\mathrm{w}}=438$, NOF Co., Tokyo, Japan) as a monomer, $\mathrm{LiClO}_{4}$ (Kishida Chemical Co., Osaka, Japan) and natural MMT (JCSS3102, cation exchange capacity $=80.7 \mathrm{meq} 100 \mathrm{~g}^{-1}$ ) as a smectite clay ${ }^{26}$ for the composite film preparation ( ${ }^{1} \mathrm{H} \mathrm{NMR}\left(300 \mathrm{MHz}, \mathrm{CDCl}_{3}\right)$ of PE-350, $\delta$ (p.p.m.): 1.95 (s, $\mathrm{CH}_{3}$ ), 2.65 (s-broad, $\left.\mathrm{OH}\right), 3.59-3.76\left(\mathrm{~m}, \mathrm{CH}_{2} \mathrm{CH}_{2} \mathrm{O}\right), 4.30\left(\mathrm{t}, \mathrm{COOCH}_{2}\right), 5.80$ and 6.13 (ss, $\left.\mathrm{CH}_{2}=\mathrm{C}\right)$ ). The original MMT was dispersed in $0.1 \mathrm{M}$ of $\mathrm{LiCl}$ aqueous solution for $24 \mathrm{~h}$ to change sodium to lithium cations. The supernatant was discarded and the gel-like lithium MMT (MMT) was placed into an oven at $100{ }^{\circ} \mathrm{C}$ for solidification. The solid sample was added to excess methanol, and the solutions were filtered. The filtrate was detected using $0.1 \mathrm{M}$ of $\mathrm{AgNO}_{3}$ solution until no chloride ions were produced in the form of $\mathrm{AgCl}$ precipitation. Finally, the MMT was dried in vacuo at $70{ }^{\circ} \mathrm{C}$ for $36 \mathrm{~h}$

\section{Preparation of original composites}

The starting monomer solutions were obtained from PE-350 ( $1 \mathrm{~g})$ dissolved in anhydrous acetone $\left(15 \mathrm{ml}\right.$ ) with $\mathrm{MMT}, \mathrm{LiClO}_{4}$ and $1 \mathrm{~mol} \%$ (of the monomer) of $\alpha, \alpha^{\prime}$-azobis(isobutyronitrile). The ratio of $\mathrm{Li}^{+}$to the oxyethylene (OE) unit of all samples was designed to be $10 \mathrm{~mol} \%([\mathrm{Li}] /[\mathrm{OE}]=0.1)$. The solvent was removed, and the resulting viscous mixture was dried in vacuo at room temperature for $24 \mathrm{~h}$. The mixture was cast onto the Teflon plate and heated from room temperature to $90^{\circ} \mathrm{C}$ under dry $\mathrm{N}_{2}$. After cooling to room temperature, the original $\mathrm{PMEO}_{10} \mathrm{LiClO}_{4}\left(\mathrm{P}_{10} \mathrm{Li}\right)$ and the MMT composites $\left(\mathrm{M}_{\text {ori }}-\mathrm{P}_{10} \mathrm{Li}\right)$ were obtained as $\sim 300-\mu \mathrm{m}$-thick films.

\section{Preparation MMT-oriented composites}

The preparation of MMT-oriented composite polymer electrolytes was basically carried out using the following three procedures: (1) MMT orientation in the monomer solution under a strong magnetic field, (2) solvent removal and (3) in situ polymerization. Two types of MMT-oriented films $\left(\mathrm{M}_{\perp}-\mathrm{P}_{10} \mathrm{Li}\right.$ and $\left.\mathrm{M}_{/ /}-\mathrm{P}_{10} \mathrm{Li}\right)$ were obtained. The difference between $\mathrm{M}_{\perp}$ (perpendicular) and $\mathrm{M}_{/ /}$(parallel) is the direction of the magnetic field to the film surface. The starting suspensions (PE-350, MMT, $\mathrm{LiClO}_{4}$ and $\alpha, \alpha^{\prime}$-azobis(isobutyronitrile)) dispersed in anhydrous acetone were cast onto the Teflon plate and then loaded into the generating equipment of the magnetic field. The equipment consists of a heating cell and a superconducting magnet (Sumitomo Heavy Industries Ltd., Tokyo, Japan) that can apply a magnetic field with a strength of $2 \mathrm{~T}$ and change the orientation of the field. The magnetic field was applied to the solution at room temperature for $1 \mathrm{~h}$. The suspension was then heated at the rate of $5^{\circ} \mathrm{C} \mathrm{min}-1$ and maintained at $90{ }^{\circ} \mathrm{C}$ for $5 \mathrm{~h}$. The samples were gradually cooled to room temperature, and polymerized films were obtained. All processes were completely carried out under dry $\mathrm{N}_{2}$.

\section{Measurements}

Wide-angle X-ray diffraction (WAXD) measurements involving an imaging plate system were carried out using an ultraX-18 (Rigaku Co., Tokyo, Japan) operated at $60 \mathrm{kV}$ and $300 \mathrm{~mA}$ to generate CuK $\alpha$ X-ray beams. The measurements were conducted from an edge view of the sample film. The X-ray azimuthal scans for $\mathrm{M}_{\perp}-\mathrm{P}_{10} \mathrm{Li}$ and $\mathrm{M}_{/ /}-\mathrm{P}_{10} \mathrm{Li}$ samples were made with the zero azimuthal angle corresponding to the direction parallel to the film surface. The ionic conductivities of all samples were measured by the AC complex impedance method using SP-150 (BioLogic SAS, Claix, France) in the frequency range $100 \mathrm{~Hz}$ to $1 \mathrm{MHz}$. The sample was sandwiched between two stainless steel electrodes with a 300- $\mu$ m-thick Teflon spacer, and the cell surface was then insulated with polyimide tape. The conductivities were measured in the direction perpendicular to the film surface. Preparation of the cell and all measurements were carried out in a dry Ar-filled glovebox. Differential scanning calorimetry measurements were carried out using a DSC120 (Seiko Inst., Chiba, Japan) in the temperature range $-100^{\circ} \mathrm{C}$ to $150{ }^{\circ} \mathrm{C}$ at a heating rate of $10^{\circ} \mathrm{C} \mathrm{min}^{-1}$.

\section{RESULTS AND DISCUSSION}

The WAXD patterns of pristine MMT and $\mathrm{P}_{10} \mathrm{Li}$ composites (20 wt $\%$ of MMT) are shown in Figure 1 . The $d$-spacing of these samples are summarized in Table 1. The peak of the $\left(\begin{array}{lll}0 & 0 & 1\end{array}\right)$ plane of pristine MMT at $7^{\circ}$ corresponding to a $d$-spacing of $12.6 \AA$ was shifted to lower angles in the respective composites. This is due to the intercalation of PMEO chains into the MMT layers. The $d$-spacing of MMT were most likely expanded by the polymerization because PE-350 monomers having several OE units were intercalated and interact with $\mathrm{Li}^{+}$in the layers. The $d$-spacing of $\mathrm{M}_{\perp}-\mathrm{P}_{10} \mathrm{Li}$ and $\mathrm{M}_{/ /}-\mathrm{P}_{10} \mathrm{Li}$ were almost the same and were slightly higher than that of $\mathrm{M}_{\text {ori }}-\mathrm{P}_{10} \mathrm{Li}$. Ahn and colleagues ${ }^{20,21}$ have reported that the application of an electric field to polypropylene/organic-modified MMT (Cloisite 20A) composites causes not only orientation of the composites but also expansion of the layer spacing in the composites. In the case of $\mathrm{M}_{\perp}-\mathrm{P}_{10} \mathrm{Li}$ and $\mathrm{M}_{/ /}-\mathrm{P}_{10} \mathrm{Li}$, the expansion may be caused by the magnetic field.

To characterize the orientation state of the MMT composites, we measured two-dimensional (2D) WAXD patterns of $\mathrm{P}_{10} \mathrm{Li}$ composites $(20 \mathrm{wt} \%)$, as shown in Figure 2. The ring patterns that appear in all the composites are attributed to the $\left(\begin{array}{lll}0 & 0 & 1\end{array}\right)$ plane of the dispersed MMT. The $\mathrm{M}_{\text {ori }}-\mathrm{P}_{10} \mathrm{Li}$ showed an isotropic ring pattern, as seen in Figure 2a, which represents random dispersion of the MMT layers. The homogeneity of the dispersion was maintained without aggregation and sedimentation of the MMT layers, regardless of the relatively high content of MMT in the composites. In the WAXD pattern of

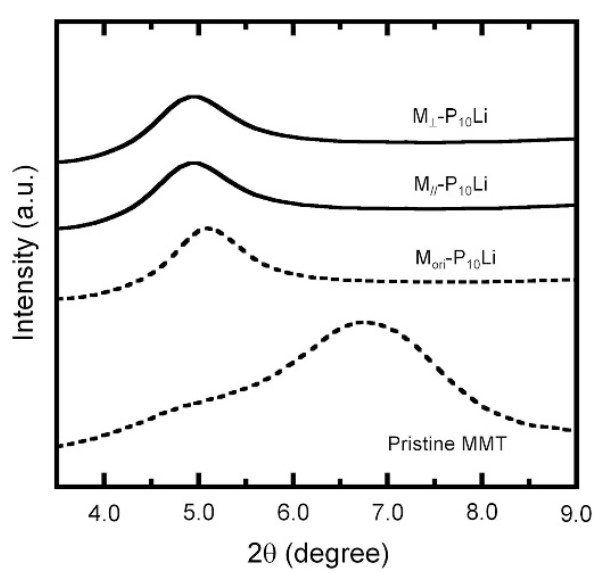

Figure 1 WAXD patterns of pristine MMT and MMT composites (20 wt\%). 
$\mathrm{M}_{/ /}-\mathrm{P}_{10} \mathrm{Li}$ in Figure $2 \mathrm{~b}$, an increase in the meridian intensity and a decrease in the equator intensity were observed. This means that the MMT layers were oriented by the magnetic field corresponding to the parallel orientation to the film surface. By contrast, the WAXD pattern of $\mathrm{M}_{\perp}-\mathrm{P}_{10} \mathrm{Li}$ in Figure $2 \mathrm{c}$ showed a decrease in the meridian intensity and an increase in the equator intensity, which indicate a perpendicular orientation of the MMT layers to the film surface. Such orientations caused by the magnetic field have already been reported as $\mathrm{Na}^{-\mathrm{MMT}^{27}}$ and other layered silicates ${ }^{22-24}$ (for example, kaolinite, talc and sericite) in aqueous suspension systems. These results clearly suggest that the MMT layers can preferentially orient along the direction of an applied magnetic field in a polymer electrolyte.

It is known that the diamagnetic anisotropic energy induced by the magnetic field is related to the Brownian rotational energy to achieve orientation of clays. ${ }^{22}$ The following inequality shows the conditions of orientation:

$$
-\left(1 / 2 \mu_{0}\right) V \Delta \chi_{\mathrm{a}} B^{2} \cos ^{2} \theta>k_{\mathrm{B}} T
$$

where $\mu_{0}$ is the magnetic permeability under vacuum, $V$ is the volume of the particles in the silicate layers, $\Delta \chi_{\mathrm{a}}$ is the diamagnetic anisotropy susceptibility, $B$ is the external magnetic field, $\theta$ is the angle between the magnetic field and the magnetic axis, $k_{\mathrm{B}}$ is the Boltzmann constant and $T$ is the experimental temperature. The $\Delta \chi_{\mathrm{a}}$ term can be defined as $\chi_{/ /}-\chi_{\perp}$, where $\chi_{/ /}$and $\chi_{\perp}$ are the diamagnetic susceptibilities parallel and perpendicular to the magnetic axis. This equation indicates that when the volume of the dispersed clays becomes larger, orientation can be achieved easily at a low field intensity. To achieve the orientation, the dispersion of clays is also a

Table 1 The $d$-spacing, $T_{\mathrm{g}}$, ionic conductivity $\sigma\left(30^{\circ} \mathrm{C}\right)$ and activation energy $E_{\mathrm{a}}$ of all samples

\begin{tabular}{|c|c|c|c|c|}
\hline Samples & d-spacing $\left(A^{\circ}\right)$ & $\left.\mathrm{T}_{g}{ }^{\circ} \mathrm{C}\right)$ & $\sigma / 10^{-7}\left(\mathrm{Scm}^{-1}\right)$ & $\mathrm{E}_{a}\left(\mathrm{~kJ} \mathrm{~mol}^{-1}\right)$ \\
\hline Pristine MMT & 12.6 & - & - & - \\
\hline Neat $\mathrm{PMEO}_{10} \mathrm{LiClO}_{4}$ & - & -40 & 12.8 & 14.4 \\
\hline$+20 w t \%$ MMT $\left(M_{\text {ori }}\right)$ & 17.3 & -45 & 5.7 & 15.9 \\
\hline + $20 \mathrm{wt} \% \mathrm{MMT}\left(\mathrm{M}_{/ /}\right)$ & 18.0 & -43 & 2.7 & 15.1 \\
\hline$+20 \mathrm{wt} \% \mathrm{MMT}\left(\mathrm{M}_{\perp}\right)$ & 18.0 & -43 & 37.4 & 9.5 \\
\hline
\end{tabular}

significant factor for the actual experiment. Kimura et al. ${ }^{25}$ have reported that the micro-ordered clays can be oriented at $\sim 1$ to $2 \mathrm{~T}$. In other words, if the clays aggregate and form isotropic particles in the matrix, the orientation cannot occur because the $\Delta \chi_{\mathrm{a}}$ of the single particle becomes zero. In this study, we applied a magnetic field to the sample in the solution state, so the MMT layers were easy to disperse and to orient with the magnetic field, even when the content of MMT was high. Moreover, the orientation was frozen by the in situ polymerization. For further analysis, the azimuthal scans on the $(0$ 0 1) planes at $4.9^{\circ}$ in $\mathrm{M}_{/ /}-\mathrm{P}_{10} \mathrm{Li}$ and $\mathrm{M}_{\perp}-\mathrm{P}_{10} \mathrm{Li}$ (20 wt\%) samples were carried out as shown in Figure 3. The $\mathrm{M}_{\perp}-\mathrm{P}_{10} \mathrm{Li}$ and $\mathrm{M}_{/ /}-\mathrm{P}_{10} \mathrm{Li}$ showed obvious azimuthal angle peaks at $188^{\circ}$ (the magnetic field direction is 0 and $180^{\circ}$ ), $89^{\circ}$ and $272^{\circ}$ (the magnetic field direction is 90 and $270^{\circ}$ ), but later, two peaks seemed to be broad. This reveals that almost all of the MMT layers in the polyether were oriented to the magnetic field direction at several degrees, and the degree of orientation in $\mathrm{M}_{\perp}-\mathrm{P}_{10} \mathrm{Li}$ was higher than that in $\mathrm{M}_{/ /}-\mathrm{P}_{10} \mathrm{Li}$. To discuss
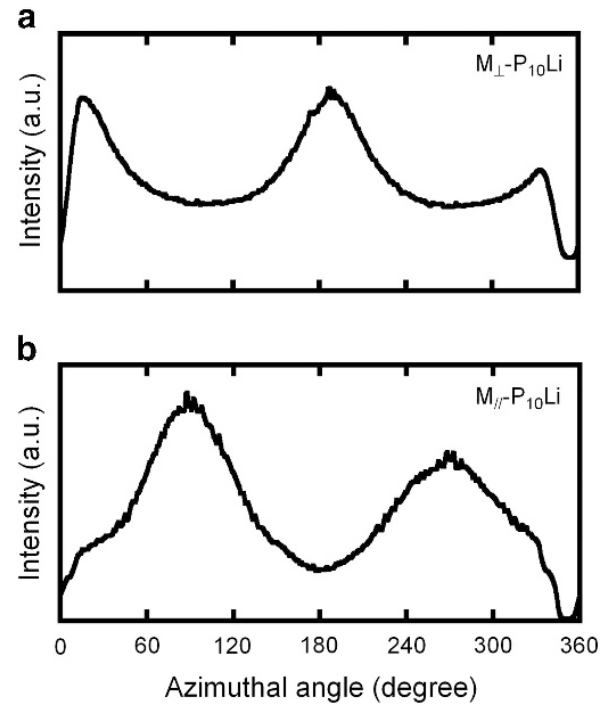

Figure 3 WAXD azimuthal scans of 2D WAXD data for (a) $\mathrm{M}_{\perp}-\mathrm{P}_{10} \mathrm{Li}$ and (b) $\mathrm{M}_{/ /}-\mathrm{P}_{10} \mathrm{Li}$ composites (20 wt\%). a

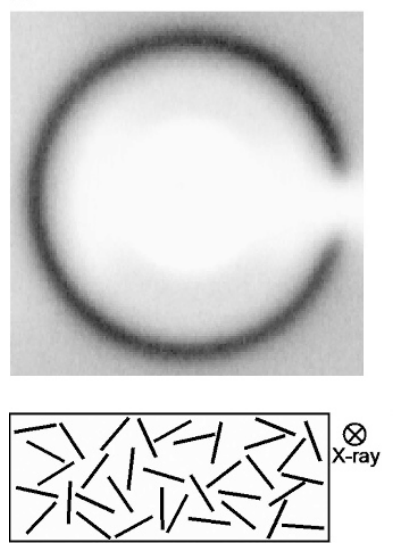

b
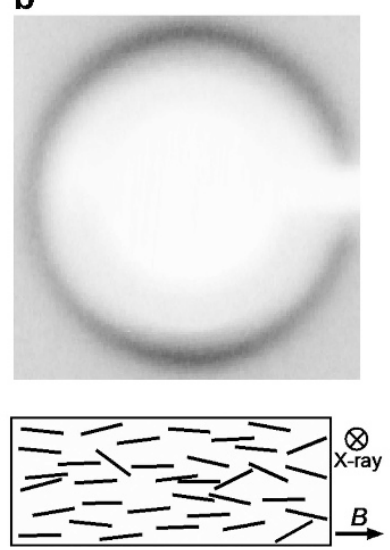

C
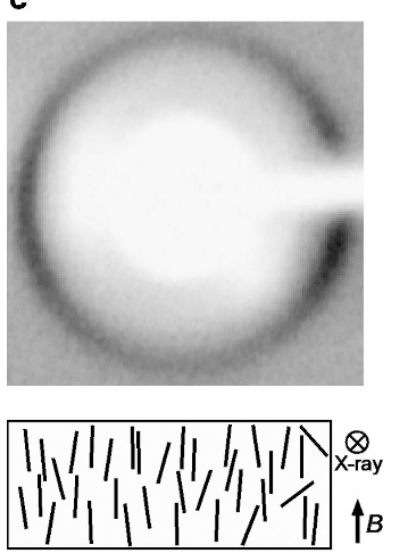

Figure 2 2D WAXD patterns and schematic images of (a) $\mathrm{M}_{\text {ori }}-\mathrm{P}_{10} \mathrm{Li}$, (b) $\mathrm{M}_{/ /} \mathrm{P}_{10} \mathrm{Li}$ and (c) $\mathrm{M}_{\perp}-\mathrm{P}_{10} \mathrm{Li}$ composites (20 wt\%). The schematic images are sections of the film samples. The MMT layers are represented by black lines. A full color version of this figure is available at Polymer Journal online. 
the orientation state more quantitatively, the peaks of $\mathrm{M}_{\perp}-\mathrm{P}_{10} \mathrm{Li}$ at $188^{\circ}$ and $\mathrm{M}_{/ /}-\mathrm{P}_{10} \mathrm{Li}$ at $89^{\circ}$ were curve-fitted to determine the full-width at half-maximum intensity of the peak by the GaussianLorenzian function. ${ }^{28,29}$ As a result, the full-width at half-maximum value of the $\mathrm{M}_{\perp}-\mathrm{P}_{10} \mathrm{Li}$ was $53.7^{\circ}$ and of the $\mathrm{M}_{/ /}-\mathrm{P}_{10} \mathrm{Li}$ was $68.6^{\circ}$. This may indicate that the distribution of orientations in $\mathrm{M}_{\perp}-\mathrm{P}_{10} \mathrm{Li}$ is slightly narrower than that in $\mathrm{M}_{/ /}-\mathrm{P}_{10} \mathrm{Li}$. The full-width at halfmaximum of the $\mathrm{M}_{\perp}-\mathrm{P}_{10} \mathrm{Li}$ is almost the same as the value of the aqueous PEO/NaMMT solution under a shear orientation. ${ }^{29}$

Figure 4 shows differential scanning calorimetry curves of neat $\mathrm{P}_{10} \mathrm{Li}$ and the composites $(20 \mathrm{wt} \%)$. The glass transition temperatures $\left(T_{\mathrm{g}}\right)$ of the composites are summarized in Table 1. Each composite sample had a single $T_{\mathrm{g}}$ at approximately $-40^{\circ} \mathrm{C}$ and had no further endothermic peaks above the $T_{\mathrm{g}}$. The $T_{\mathrm{g}}$ of neat $\mathrm{P}_{10} \mathrm{Li}$ was $-40^{\circ} \mathrm{C}$, and the value clearly decreased $3-5{ }^{\circ} \mathrm{C}$ from the addition of MMT. This may contribute to the destruction of cross-linking structures between polyethers and ions, which prevent the segmental motion of the ether chains. ${ }^{30}$ The $T_{\mathrm{g}}$ values of $\mathrm{M}_{/ /}-\mathrm{P}_{10} \mathrm{Li}$ and $\mathrm{M}_{\perp}-\mathrm{P}_{10} \mathrm{Li}$ were slightly higher than that of $\mathrm{M}_{\text {ori }}-\mathrm{P}_{10} \mathrm{Li}$, and the transition changes seem to be sharp. This indicates that the amorphous regions in which carrier ions can migrate faster increased, but the mobility of polymer chains slightly decreased through the application of a magnetic field. However, there were no differences in the $T_{\mathrm{g}}$ and the conductivity between neat $\mathrm{P}_{10} \mathrm{Li}$ and the $\mathrm{P}_{10} \mathrm{Li}$ with a magnetic field applied (data not shown). These results indicate that the dynamics of polymer chains in the MMT composites are mainly influenced by the orientation state of MMT and not by the application of a magnetic field. The orientation may change the local structures of polyether around the MMT layers and contribute to the increase in the $T_{\mathrm{g}}$ and amorphous regions in the composites.

The temperature dependence of the ionic conductivity for neat $\mathrm{P}_{10} \mathrm{Li}$ and the composites $(20 \mathrm{wt} \%)$ are shown in Figure 5. The conductivity values at $30^{\circ} \mathrm{C}$ are summarized in Table 1 . The conductivity of the MMT composites was lower than that of the neat $\mathrm{P}_{10} \mathrm{Li}$ for the temperature range measured. Several papers have reported on the difficulty of improving the conductivity of corresponding polyether/salt systems with the simple addition of clay without any treatments. ${ }^{31,32}$ Wendy et al. have reported that the decrease in the conductivity of $\mathrm{PEO}-\mathrm{NaClO}_{4}$ composites filled with
Na-MMT may be owing to the strong interaction between the cations of salts and the anionic layers of MMT, which restricts the mobility of the cations. ${ }^{31}$ Using FT-IR measurements, Hsien-Wei et al. have shown that the anionic layers of MMT modified by poly(propylene oxide) having quaternary diammonium cations promote the dissociation of $\mathrm{LiClO}_{4}$ contributing to the specific interaction between $\mathrm{Li}^{+}$ and the anionic layers. ${ }^{32}$ The number of carrier ions should potentially increase from the addition of MMT because of the intercalation of cations into the MMT layers. According to these reports, we think that there may be complicated local structures formed around the anionic layers, which interact with the dissociated ions and simultaneously form immobile complex domains. In this study, the excess negative charges in the MMT layers most likely restricted the ionic migration, which decreased the number of carrier ions and resulted in a decrease in the conductivity. This consideration can be confirmed by the decrease in the $T_{\mathrm{g}}$, as shown in Figure 4 . As seen in Figure 5, it is clear that the conductivity of $\mathrm{M}_{/ /}-\mathrm{P}_{10} \mathrm{Li}$ is the lowest of all of the samples. In contrast, the $\mathrm{M}_{\perp}-\mathrm{P}_{10} \mathrm{Li}$ showed relatively good conductivity, and the value was higher than that of the neat $\mathrm{P}_{10} \mathrm{Li}$ at $30^{\circ} \mathrm{C}$. It is well known that the ionic conduction in conventional polyether/metal salt complexes strongly correlates with the segmental motion of polyether chains. In other words, the $T_{\mathrm{g}}$, which is related to the segmental motion, has a key role in the electrolyte system. Although the conductivity value of the $\mathrm{M}_{\perp}-\mathrm{P}_{10} \mathrm{Li}$ is $\sim 15$ times higher than that of the $\mathrm{M}_{/ /}-\mathrm{P}_{10} \mathrm{Li}$ at $30^{\circ} \mathrm{C}$, there are no differences in the $T_{\mathrm{g}}$ between these composites, as seen in Table 1 and Figure 4 . We think that the obvious difference in the conductivity between $\mathrm{M}_{/ /}-\mathrm{P}_{10} \mathrm{Li}$ and $\mathrm{M}_{\perp}-\mathrm{P}_{10} \mathrm{Li}$ is due to the orientation direction of MMT layers. Aranda et al. ${ }^{9}$ have studied the significant difference in the conductivity of the PEO/MMT systems for directions perpendicular and parallel to the anionic layers. Shriver and colleagues $^{18}$ have also suggested that the difference in the conductivity of polyphosphazene/MMT composites is due to the tortuosity of ionic migration, which is caused by the orientation direction of the MMT layers. As seen in Figures 2 and 5 of this study, there are substantial correlations between the conductivity and the ratio of MMT layers oriented along the direction of the conductivity measurement. The lowest conductivity was observed in the $\mathrm{M}_{/ /}-\mathrm{P}_{10} \mathrm{Li}$, which had MMT layers oriented perpendicular to the measurement

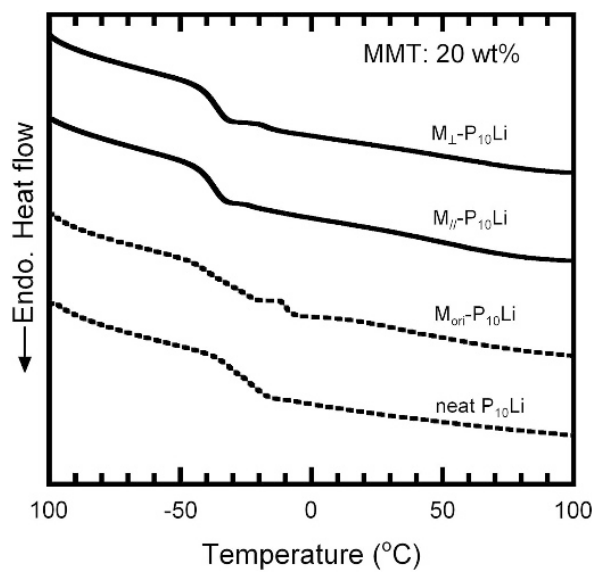

Figure 4 Differential scanning calorimetry curves of neat $\mathrm{P}_{10} \mathrm{Li}, \mathrm{M}_{\text {ori }}-\mathrm{P}_{10} \mathrm{Li}$, $\mathrm{M}_{/ /}-\mathrm{P}_{10} \mathrm{Li}$ and $\mathrm{M}_{\perp}-\mathrm{P}_{10} \mathrm{Li}$ composites (20 wt\%).

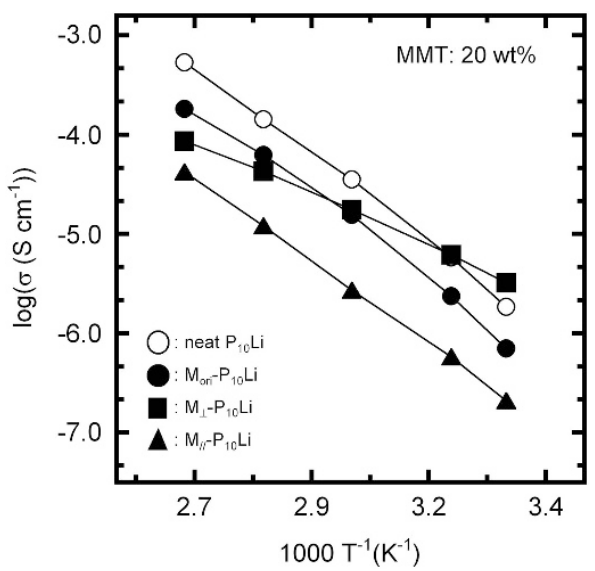

Figure 5 Temperature dependence of ionic conductivity for neat $\mathrm{P}_{10} \mathrm{Li}$, $\mathrm{M}_{\text {ori }}-\mathrm{P}_{10} \mathrm{Li}, \mathrm{M}_{/ /}-\mathrm{P}_{10} \mathrm{Li}$ and $\mathrm{M}_{\perp}-\mathrm{P}_{10} \mathrm{Li}$ composites (20 wt\%). 
direction of the conductivity. The $\mathrm{M}_{\text {ori }}-\mathrm{P}_{10} \mathrm{Li}$ produced a medium conductivity value because of the random dispersion of MMT layers. To discuss the conduction behavior of the MMT composites, the temperature dependence can be described by the Vogel-TammanFulcher empirical equation, which is commonly used for amorphous polymer electrolytes:

$$
\ln \left(\sigma^{1 / 2}\right)=-E_{\mathrm{a}} / R\left(T-T_{0}\right)+\ln A
$$

where $A$ is a constant that is proportional to the number of carrier ions, $T_{0}$ is an ideal $T_{\mathrm{g}}, R\left(\mathrm{~J} \mathrm{~mol}^{-1} \mathrm{~K}\right)$ is the fundamental gas constant and $E_{\mathrm{a}}\left(\mathrm{kJ} \mathrm{mol}^{-1}\right)$ is the activation energy for ionic migration via the segmental motion. ${ }^{4}$ The parameter $E_{\mathrm{a}}$ can be estimated from the gradient of each linear plot based on equation (2), and $E_{\mathrm{a}}$ values are summarized in Table 1. The Vogel-Tamman-Fulcher fitting results show that ionic conduction mainly occurs in the amorphous phase of the composites and that ionic conduction is certainly affected by the segmental motion of polymer chains. The $E_{\mathrm{a}}$ of $\mathrm{M}_{\text {ori }}-\mathrm{P}_{10} \mathrm{Li}$ was slightly higher than that of the neat $\mathrm{P}_{10} \mathrm{Li}$ and $\mathrm{M}_{/ /}-\mathrm{P}_{10} \mathrm{Li}$. In contrast, the $E_{\mathrm{a}}$ of $\mathrm{M}_{\perp}-\mathrm{P}_{10} \mathrm{Li}$ was below $10 \mathrm{~kJ} \mathrm{~mol}^{-1}$ and was the lowest of all of the composites and neat $\mathrm{P}_{10} \mathrm{Li}$. This means that the mechanism of ionic conduction in $\mathrm{M}_{\perp}-\mathrm{P}_{10} \mathrm{Li}$ is clearly different from the other composites and that it most likely occurs not only in the amorphous region but also in the layers of dispersed MMT, which is not due to the segmental motion of the polymer chains. Therefore, it is obvious that the orientation of dispersed MMT strongly affects the $\mathrm{Li}^{+}$or $\mathrm{ClO}_{4}{ }^{-}$conduction occurring on the layers. From these results, the ionic conduction on the MMT layers (inner and outer) was able to contribute to the improvement in the $\mathrm{M}_{\perp}-\mathrm{P}_{10} \mathrm{Li}$. In the case of the amorphous region in SPEs, it is known that dissociated ions can migrate randomly via the segmental motion of polymer chains. However, some reports have shown that the confinement of the microstructure consisting of the self-assembly of molecules also enhances the conductivity. ${ }^{33-35}$ In this study, we think that the confinement structure, which is based on the layered MMT, can effectively act as an ion-conduction pathway in the composites.

Figure 6 summarizes the relationship between the MMT content and the conductivity at $30^{\circ} \mathrm{C}$ for the $\mathrm{P}_{10} \mathrm{Li}$ composites. The conductivity of all of the composites decreased gradually as the MMT content increased. This is attributed to the increase in the tortuosity effect from the increase in the content of dispersed MMT. The conductivities of $\mathrm{M}_{\text {ori }}-\mathrm{P}_{10} \mathrm{Li}$ and $\mathrm{M}_{/ /}-\mathrm{P}_{10} \mathrm{Li}$ were lower than that of neat $\mathrm{P}_{10} \mathrm{Li}$, but the $\mathrm{M}_{\perp}-\mathrm{P}_{10} \mathrm{Li}$ showed a higher conductivity at all

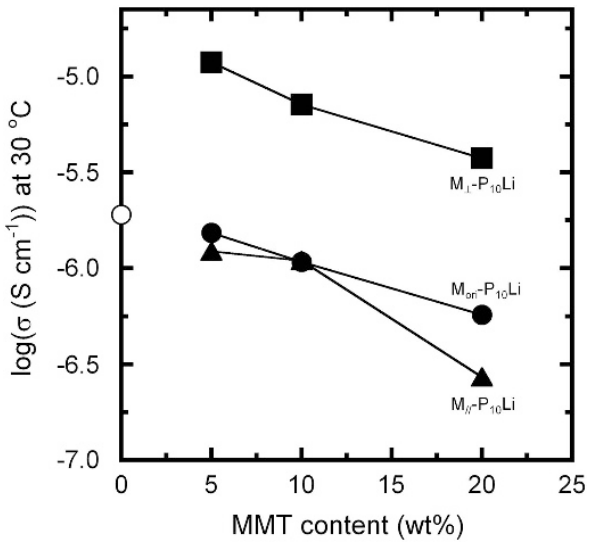

Figure 6 Relationship between the conductivity at $30^{\circ} \mathrm{C}$ and MMT content for $\mathrm{M}_{\text {ori }}-\mathrm{P}_{10} \mathrm{Li}, \mathrm{M}_{/ /}-\mathrm{P}_{10} \mathrm{Li}$ and $\mathrm{M}_{\perp}-\mathrm{P}_{10} \mathrm{Li}$ composites.
MMT content values. In particular, the conductivity value of $\mathrm{M}_{\perp}-$ $\mathrm{P}_{10} \mathrm{Li}$ with $5 \mathrm{wt} \%$ MMT was the highest $\left(1.2 \times 10^{-5} \mathrm{Scm}^{-1}\right)$ and was more than six times greater than that of the neat $\mathrm{P}_{10} \mathrm{Li}$.

\section{CONCLUSIONS}

Composite polymer electrolytes filled with MMT were prepared, and orientation of the MMT layers perpendicular $\left(\mathrm{M}_{\perp}\right)$ and parallel $\left(\mathrm{M}_{/ /}\right)$ to the film surface was successfully performed using a strong magnetic field. The 2D WAXD measurements showed that the MMT layers preferentially oriented along the magnetic field direction in the composites. From further analysis of the 2D WAXD measurements, the orientation state of the MMT layers in the composites was determined using the azimuthal angle data. The conductivity measurement revealed that the $\mathrm{M}_{\perp}$ composite shows good conductivity, and the value is higher than that of the neat samples $\left(\mathrm{PMEO}_{10} \mathrm{Li}\right.$ $\mathrm{ClO}_{4}$ ) at $30^{\circ} \mathrm{C}$. The MMT original composites (without orientation) showed a medium value of the conductivity among the oriented composites because of the random dispersion of MMT layers. These results clearly suggest that the MMT layers oriented parallel to the direction of the conductivity measurement enhanced the conductivity of the composites. In particular, the conductivity value of the $\mathrm{M}_{\perp}$ composite with $5 \mathrm{wt} \%$ MMT was $1.2 \times 10^{-5} \mathrm{~S} \mathrm{~cm}^{-1}$ at $30^{\circ} \mathrm{C}$, which was more than six times higher than that of the neat electrolyte. We concluded that the ionic migration on the layer of oriented MMT has a crucial role in increasing the conductivity with a lower activation energy.

\section{CONFLICT OF INTEREST}

The authors declare no conflict of interest.

\section{ACKNOWLEDGEMENTS}

This work was financially supported by a Grant-in-Aid for Young Scientists (B) (No. 21750113) from the Ministry of Education, Culture, Sport, Science and Technology, Japan.

1 Armand, M. B., Chagagno, J. M. \& Duclot, M. T. In Fast Ion Transport in Solids (eds Vashishta, P., Mumdy, J. N. \& Shennoy, G. K.) 131 Amsterdam, North-Holland, 1979).

2 Tarascon, J. M. \& Armand, M. Issues and challenges facing rechargeable lithium batteries. Nature 414, 359-367 (2001)

3 Ratner, M. A. \& Shriver, D. F. Ion-transport in solvent-free polymers. Chem. Rev. 88, 109-124 (1988).

4 Bruce, P. G. Solid State Electrochemistry (Cambridge University Press, Cambridge, 1995).

5 Croce, F., Scrosati, B. \& Mariotto, G. Electrochemical and spectroscopic study of the transport-properties of composite polymer electrolytes. Chem. Mater. 4, 1134-1136 (1992)

6 Croce, F., Appetecchi, G. B., Persi, L. \& Scrosati, B. Nanocomposite polymer electrolytes for lithium batteries. Nature 394, 456-458 (1998).

7 Marcinek, M., Bac, A., Lipka, P., Zalewska, A., Zukowska, G., Borkowska, R. \& Wieczorek, W. Effect of filler surface group on ionic interactions in PEG-LiClO ${ }_{4}-\mathrm{Al}_{2} \mathrm{O}_{3}$ composite polyether electrolytes. J. Phys. Chem. B 104, 11088-11093 (2000).

8 Tominaga, Y., Igawa, S., Asai, S. \& Sumita, M. Ion-conductive properties of mesoporous silica-filled composite polymer electrolytes. Electrochim. Acta 50, 3949-3954 (2005).

9 Aranda, P. \& Ruizhitzky, E. Poly(ethylene oxide)-silicate intercalation materials. Chem Mater. 4, 1395-1403 (1992).

$10 \mathrm{Wu}$, J. H. \& Lerner, M. M. Structural, thermal, and electrical characterization of layered nanocomposites derived from Na-montmorillonite and polyethers. Chem. Mater. 5, 835-838 (1993)

11 Giannelis, E. P. Polymer layered silicate nanocomposites. Advan. Mater. 8, 29-35 (1996).

12 Kuppa, V. \& Manias, E. Computer simulation of PEO/layered-silicate nanocomposites 2. Lithium dynamics in $\mathrm{PEO} / \mathrm{Li}^{+}$montmorillonite intercalates. Chem. Mater. 14, 2171-2175 (2002)

13 Vaia, R. A., Sauer, B. B., Tse, O. K. \& Giannelis, E. P. Relaxations of confined chains in polymer nanocomposites: glass transition properties of poly(ethylene oxide) intercalated in montmorillonite. J. Polym. Sci. B-Polym. Phys. 35, 59-67 (1997). 
14 Anastasiadis, S. H., Karatasos, K., Vlachos, G., Manias, E. \& Giannelis, E. P. Nanoscopic-confinement effects on local dynamics. Phys. Rev. Lett. 84, 915-918 (2000).

15 Elmahdy, M. M., Chrissopoulou, K., Afratis, A., Floudas, G. \& Anastasiadis, S. H. Effect of confinement on polymer segmental motion and ion mobility in PEO/layered silicate nanocomposites. Macromolecules 39, 5170-5173 (2006)

16 Kitajima, S. \& Tominaga, Y. Enhanced cationic conduction in a polyether/clay composite electrolyte treated with supercritical $\mathrm{CO}_{2}$. Macromolecules 42, 5422-5424 (2009).

17 Kitajima, S. \& Tominaga, Y. Improvement in dispersion and ionic conductivity of polyether/freeze-dried clay composites using supercritical carbon dioxide as treatment medium. Ionics 18, 845-851 (2012).

18 Hutchison, J. C., Bissessur, R. \& Shriver, D. F. Conductivity anisotropy of polyphosphazene-montmorillonite composite electrolytes. Chem. Mater. 8, 1597-1599 (1996).

19 Sun, T., Chen, F., Dong, X., Zhou, Y., Wang, D. \& Han, C. C. Shear-induced orientation in the crystallization of an isotactic polypropylene nanocomposite. Polymer (Guildf) 50, 2465-2471 (2009).

20 Kim, D. H., Park, J. U., Ahn, K. H. \& Lee, S. J. Electrically activated poly(propylene)/ clay nanocomposites. Macromol. Rapid Commun. 24, 388-391 (2003).

21 Park, J. U., Choi, Y. S., Cho, K. S., Kim, D. H., Ahn, K. H. \& Lee, S. J. Time-electric field superposition in electrically activated polypropylene/layered silicate nanocomposites. Polymer (Guildf) 47, 5145-5153 (2006).

22 Uyeda, C., Takeuchi, T., Yamagishi, A. \& Date, M. Diamagnetic orientation of clay mineral grains. J. Phys. Soc. Jpn 60, 3234-3237 (1991).

23 Uyeda, C., Ohtawa, K., Okita, K. \& Uyeda, N. Diamagnetic anisotropy derived from single chemical bonds in the silicate tetrahedral networks. J. Phys. Soc. Jpn 70, 889-892 (2001).

24 Uyeda, C., Tanaka, K., Takashima, R. \& Sakakibara, M. Characteristics of paramagnetic and diamagnetic anisotropy which induce magnetic alignment of micron-sized nonferromagnetic particles. Mater. Trans. 44, 2594-2598 (2003).

25 Kimura, T., Uemura, T., Takagi, S. \& Inoue, H. Magnetic alignment of rhodamine B intercalated in synthetic mica. Macromol. Symp. 242, 120-125 (2006).
26 Ebina, T., Minja, R. J. A., Nagase, A. T., Onodera, Y. \& Chatterjee, A. Correlation of hydraulic conductivity of clay-sand compacted specimens with clay properties. Appl. Clay Sci. 26, 3-12 (2004).

27 Takahashi, T., Ohkubo, T. \& Ikeda, Y. Montmorillonite alignment induced by magnetic field: evidence based on the diffusion anisotropy of water molecules. J. Colloid Interface Sci. 299, 196-203 (2006).

28 Dadmun, M. D. \& Han, C. C. A neutron-scattering study of the orientation of a liquid-crystalline polymer by shear-flow. Macromolecules 27, 7522-7532 (1994).

29 Malwitz, M. M., Butler, P. D., Porcar, L., Angelette, D. P. \& Schmidt, G. Orientation and relaxation of polymer-clay solutions studied by rheology and small-angle neutron scattering. J. Polym. Sci. B-Polym. Phys. 42, 3102-3112 (2004).

30 Tominaga, Y., Izumi, Y., Kwak, G. H., Asai, S. \& Sumita, M. Effect of supercritical carbon dioxide processing on ionic association and conduction in a crystalline poly(ethylene oxide) - $\mathrm{LiCF}_{3} \mathrm{SO}_{3}$ complex. Macromolecules 36, 8766-8772 (2003).

31 Chen, H. W., Chiu, C. Y., Wu, H. D., Shen, I. W. \& Chang, F. C. Solid-state electrolyte nanocomposites based on poly(ethylene oxide), poly(oxypropylene) diamine, mineral clay and lithium perchlorate. Polymer (Guildf) 43, 5011-5016 (2002).

32 Loyens, W., Maurer, F. H. J. \& Jannasch, P. Melt-compounded salt-containing poly(ethylene oxide)/clay nanocomposites for polymer electrolyte membranes. Polymer (Guildf) 46, 7334-7345 (2005).

33 Ohtake, T., Ogasawara, M., Ito-Akita, K., Nishina, N., Ujiie, S., Ohno, H. \& Kato, T. Liquid-crystalline complexes of mesogenic dimers containing oxyethylene moieties with $\mathrm{LiCF}_{3} \mathrm{SO}_{3}$ : self-organized ion conductive materials. Chem. Mater. 12, 782-789 (2000).

34 Kishimoto, K., Suzawa, T., Yokota, T., Mukai, T., Ohno, H. \& Kato, T. Nano-segregated polymeric film exhibiting high ionic conductivities. J. Am. Chem. Soc. 127, 15618-15623 (2005).

35 Majewski, P. W., Gopinadhan, M., Jang, W. S., Lutkenhaus, J. L. \& Osuji, C. O. Anisotropic ionic conductivity in block copolymer membranes by magnetic field alignment. J. Am. Chem. Soc. 132, 17516-17522 (2010). 